\title{
Low major histocompatibility complex class II DQA diversity in the Giant Panda (Ailuropoda melanoleuca) Liang Zhu ${ }^{\dagger 1,2}$, Xiang-Dong Ruan ${ }^{\dagger 1,2}$, Yun-Fa Ge $\mathrm{G}^{1,2}$, Qiu-Hong Wan*1,2 and Sheng-Guo Fang*1,2
}

Address: ${ }^{1}$ College of Life Sciences, Zhejiang University, Hangzhou 310058, PR China and ${ }^{2}$ State Conservation Center for Gene Resources of Endangered Wildlife and the Key Laboratory of Conservation Genetics and Reproductive Biology for Endangered Wild Animals, Ministry of Education, Hangzhou 310058, PR China

Email: Liang Zhu - imzl@eyou.com; Xiang-Dong Ruan - xiangdong.ruan@yahoo.com.cn; Yun-Fa Ge - yunfa.ge@yahoo.com.cn; QiuHong Wan* - qiuhongwan@zju.edu.cn; Sheng-Guo Fang* - sgfang@mail.hz.zj.cn

* Corresponding authors †Equal contributors

Published: 7 June 2007

BMC Genetics 2007, 8:29 doi:10.1/86/147/-2156-8-29
Received: 9 March 2007

Accepted: 7 June 2007

This article is available from: http://www.biomedcentral.com/I47I-2I56/8/29

(C) 2007 Zhu et al; licensee BioMed Central Ltd.

This is an Open Access article distributed under the terms of the Creative Commons Attribution License (http://creativecommons.org/licenses/by/2.0), which permits unrestricted use, distribution, and reproduction in any medium, provided the original work is properly cited.

\begin{abstract}
Background: The giant panda (Ailuropoda melanoleuca) is one of the most endangered animals due to habitat fragmentation and loss. Although the captive breeding program for this species is now nearly two decades old, researches on the genetic background of such captive populations, especially on adaptive molecular polymorphism of major histocompatibility complex (MHC), are still limited. In this study, we characterized adaptive variation of the giant panda's MHC DQA gene by PCR amplification of its antigen-recognizing region (i.e. the exon 2 ) and subsequent single-strand conformational polymorphism (SSCP) and sequence analyses.

Results: The results revealed a low level of DQA exon 2 diversity in this rare animal, presenting 6 alleles from $6 \mathrm{I}$ giant panda individuals. The observed polymorphism was restricted to 9 amino acid substitutions, all of which occurred at and adjacent to positions forming the functionally important antigen-binding sites. All the samples were in Hardy-Weinberg proportions. A significantly higher rate of non-synonymous than synonymous substitutions at the antigen-binding sites indicated positive selection for diversity in the locus.

Conclusion: The $D Q A$ allelic diversity of giant pandas was low relative to other vertebrates. Nonetheless, the pandas exhibited more alleles in DQA than those in DRB, suggesting the alpha chain genes would play a leading role when coping with certain pathogens and thus should be included in conservation genetic investigation. The microsatellite and MHC loci might predict longterm persistence potential and short-term survival ability, respectively. Consequently, it is recommended to utilize multiple suites of microsatellite markers and multiple MHC loci to detect overall genetic variation in order to design unbiased conservation strategies.
\end{abstract}

\section{Background}

Genes of the major histocompatability complex (MHC) are known to be involved intimately in the central control of the immune response, influencing host response to infectious disease challenge. These genes are highly polymorphic in vertebrates [1]. This genetic variation alters the peptide-binding site of the encoded proteins, enabling them to bind a variety of foreign peptides [2]. Many stud- 
ies support the general hypothesis that allelic diversity at MHC genes is maintained by parasite-mediated balancing selection [3-7]. It has been suggested that species with low MHC polymorphism may be particularly vulnerable to infectious diseases $[8,9]$.

The giant panda (Ailuropoda melanoleuca) once had a wide distribution in southwest China, including Hunan, Hubei, Sichuan, Shaanxi and Gansu provinces in the 1619th centuries. However, habitat destruction and fragmentation have extirpated it from most of its original range [10] and the population of giant panda has decreased sharply. In the 1980s the global population of giant pandas was estimated to be about 1000 [10]. Now giant pandas are restricted to the isolated Qinling, Minshan, Qionglai, Daxiangling, Xiaoxiangling and Liangshan mountains (Figure 1). The historical separation between the Qinling and other populations has yielded a new Qinling subspecies from the nominate Sichuan subspecies $[12,13]$. A captive breeding program was initiated in 1980's. Now two biggest captive populations are bred in the Ya'an-Wolong and Chengdu breeding bases in Sichuan Province, containing 57 and 86 pandas, respectively [14]. The population size of wild giant pandas of Qinling subspecies was approximately 200 [10], having no captive populations but raising few rescued individuals in Louguantai base.

Pathological researches of captive giant pandas demonstrated that $44 \%$ of giant pandas had infected with pneumonia and tick-born disease and the mortality rate of

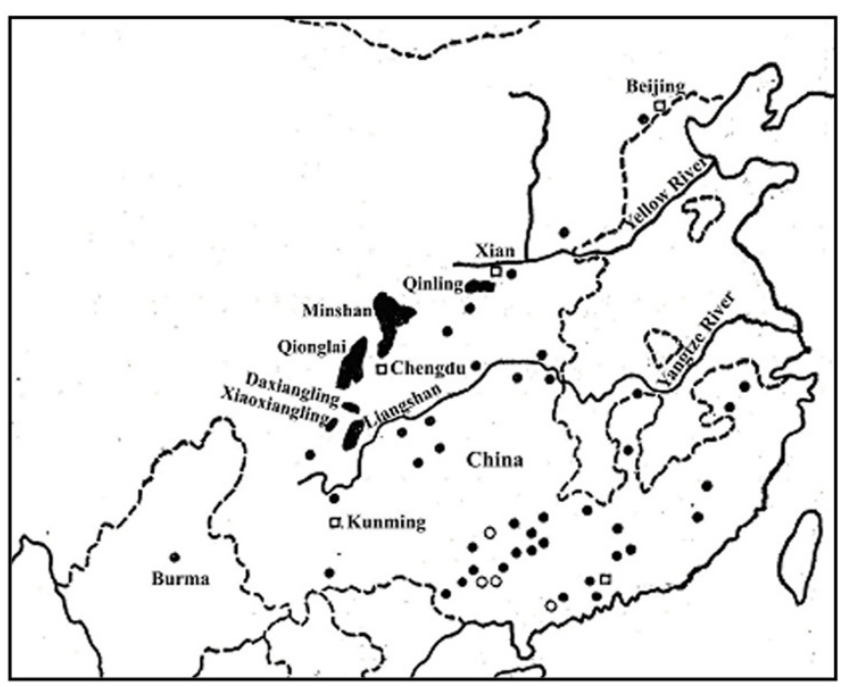

Figure I

Current and historical distribution of the giantpanda [I I]. Black areas, present distribution; White circle indicates fossil records in the Early Pleistocene and solid circle shows fossil records in the Mid and Late Pleistocene. ascariasis had attained to $66.67 \%[15,16]$. This showed that the giant pandas in captivity were particularly susceptible to infectious disease and parasites. Although different neutral DNA marker systems such as mitochondrial DNA [17], minisatellites [12] and microsatellites [18] were used to examine genetic background of giant pandas and revealed that the observed population reduction had a negative impact on genetic variation in the giant panda, neutral molecular markers can not reflect adaptive molecular polymorphism of MHC and thus fail to tell changes in fitness traits [19-21].

The MHC is divided into three classes of genes; one of these, the class II genes, encodes glycoproteins on the surface of cells [5]. Within this gene region, two subregions, DR and DQ, exhibit high levels of polymorphism [22]. Despite a wealth of references documenting allelic polymorphism in carnivore DQA genes [23-28], relatively little is known about their counterparts in the bears, especially in the giant panda.

Diversity of MHC DRB gene, the most polymorphic locus, has been studied for the giant panda in our laboratory [29]. As a result, in this study, we used the same techniques to investigate genetic variation of another polymorphic DQA locus in the giant panda using single-strand conformational polymorphism (SSCP) and sequence analyses. This study provided an insight into the level of giant panda MHC polymorphism and gave some possible implications for captive management of giant pandas.

\section{Results}

Sequence variation of $D Q A$ exon 2 was examined by SSCP, revealing 6 different alleles Aime-DQA1 AimeDQA6 (Figure 2). All sequences have been deposited in GenBank (Accession number: EF554075-EF4080). The Ya'an-Wolong and Chengdu populations of Sichuan subspecies presented 4 and 5 alleles, respectively, and shared 4 ones with each other (Table 2). The Louguantai population of Qinling subspecies showed 6 alleles, involving all of alleles from Sichuan subspecies (Table 2). The 6 Louguantai alleles showed relatively even frequencies, while alleles Aime-DQA1 Aime-DQA5 were unevenly distributed in both Sichuan populations (Table 2). Table 2 indicated lower observed $\left(H_{O}\right)$ than expected $\left(H_{E}\right)$ heterozygosities in the studied populations but revealed no significant deviations from Hardy-Weinberg equilibrium in any groups.

The polymorphism at class II loci occurs predominately in the exon 2, which encodes a majority of the peptide region [30]. The entire exon 2 translates into a sequence length of 87 amino acids with 21 possible binding sites for foreign peptide presentation [31]. Here the exon 2 region produce 76 amino acids with $20 \mathrm{ABS}$ (Figure 2) if 


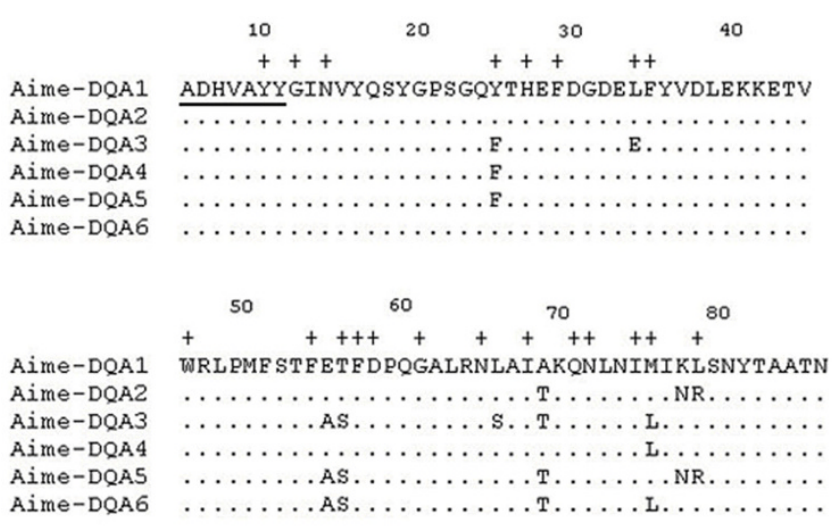

Figure 2

Comparison of exon 2 amino acid sequences of giant panda DQA alleles. Underlined indicates the upstream primer binding sites (the downstream primer was located on the intron 2 and thus excluded from amino acid sequences). A dot represents identity with the top sequence and a cross indicates putative sites involved in peptide binding as proposed for the human DQ $\alpha$ molecules [29].

excluding the upstream primer binding sites. Alignments of nucleotide and amino acid sequences showed that the polymorphism was restricted to 11 nucleotide substitutions, together causing 9 amino acid substitutions (Figure 2 ). All the amino acid variation was found at ABS and adjacent to them (Figure 2). Of the 20 ABS, 5 (25\%) were variable over the 6 alleles, whereas only $4(7.1 \%)$ of the remaining 56 positions (those not thought to interact with ABS) were polymorphic. The giant panda DQA alleles obtained shared 95.7 to $99.1 \%$ nucleotide identity in the 234 bp exon 2 sequences (excluding the primer binding sequences), corresponding to 89.7 to $97.4 \%$ amino acid identity. The relative frequency of nonsynonymous substitutions $\left(d_{N}\right)$ was significantly higher than that of synonymous ones $\left(d_{S}\right)$ in the antigen-binding site for all three populations (Table 3), consistent with the proposed maintenance of high variation by diversifying selection.

\section{Discussion}

In the human DQ $\alpha$ chain (DQA gene encoded), residues in the positions $7,30,65,72,75$ and 76 are crucial for protein to form functional conformation and bind a for- eign peptide [31]. The amino acid sequences of the giant panda showed identical residues or similar hydrophobic ones to those of human at these positions. None of the nucleotide sequences showed deletions, insertions, or stop codons. Moreover, in the functionally important antigen recognition and binding sites, the polymorphism over all alleles revealed a significantly higher rate of nonsynonymous than synonymous substitutions (Table $3 ; P<$ $0.05)$, providing evidence for positive selection pressure on these gene loci. Consequently, all of these implied a functional role for these molecules in pathogen-specific immune responses.

The giant panda DQA allelic diversity was low compared with that of other vertebrates have been investigated. For instance, the number of alleles in ovin and horse were 24 and 18 , respectively, and their numbers of variable amino acids were $37 \%$ and $46 \%$, respectively [32,33]. Differently, the giant panda only had 6 DQA alleles and $13.6 \%$ of variable amino acid positions, indicating that giant pandas had a limited capacity of recognizing diverse pathogens. Some studies showed that polymorphism was more extensive in class II beta chain genes than in the alpha chain genes [34,35], implying that the $D R B$ loci should have more alleles than DQA. However, our data seems to challenge this prediction. Although the Ya'anWolong population had more $D R B$ alleles than DQA ones, both Chengdu and Louguantai populations had more DQA alleles and DRB ones (Table 4), suggesting that the alpha chain genes would play a leading role when coping with certain pathogens and thus should be included in genetic investigation when intending to design management strategies.

Microsatellites and MHC are neutral molecular markers and functional genes, respectively, but they both possess high variability and bi-parental genetic information, thus gradually becoming powerful tools in the examination of genetic diversity and population structure. The microsatellite heterozygosity showed that the three populations had similar level of genetic diversity while the heterozygosities of MHC loci indicated that the Louguantai population kept the most abundant genetic variation (Table 4). Regarding the Ya'an-Wolong and Chengdu populations, the $D R B$ and $D Q A$ gave inconsistent results: the former

Table I: A list of samples analyzed. A shows the number of adults sampled and B indicated the number of pandas involved in captive breeding program.

\begin{tabular}{|c|c|c|c|c|}
\hline Subspecies & Location & Collection year & Sample size & Sample type \\
\hline \multirow[t]{3}{*}{ Sichuan } & Ya'an-Wolong & 2004 & $20(A=8 ; B=7)$ & Faeces \\
\hline & Chengdu & $2002 \& 2004$ & $14(A=10 ; B=8)$ & Blood \\
\hline & & 2004 & $12(\mathrm{~A}=9 ; \mathrm{B}=7)$ & Faeces \\
\hline \multirow[t]{2}{*}{ Qinling } & Louguantai & $|990-200|$ & I3 (all wild-born) & Skin \\
\hline & & 2004 & $2(A=1 ; B=1)$ & Faeces \\
\hline
\end{tabular}


Table 2: The allelic frequencies, and the observed $\left(H_{\mathrm{O}}\right)$ and expected $\left(H_{\mathrm{E}}\right)$ heterozygosities for the three populations of giant pandas.

\begin{tabular}{lcccccccccc}
\hline Subspecies & Location & Aime- DQAI & Aime- DQA2 & Aime- DQA3 & Aime- DQA4 & Aime- DQA5 & Aime- DQA6 & $H_{O}$ & $H_{E}$ & $P$ \\
\hline \multirow{2}{*}{ Sichuan } & Ya'an-Wolong & 0.400 & 0.325 & 0.000 & 0.175 & 0.100 & 0.000 & 0.650 & 0.712 & 0.242 \\
& Chengdu & 0.115 & 0.173 & 0.385 & 0.250 & 0.077 & 0.000 & 0.692 & 0.755 & 0.093 \\
\multirow{2}{*}{ Qinling } & Louguantai & 0.167 & 0.233 & 0.133 & 0.167 & 0.133 & 0.167 & 0.800 & 0.855 & 0.822 \\
\hline
\end{tabular}

had higher $D R B$ heterozygosity but the latter exhibited higher DQA heterozygosity (Table 4). From an allelic perspective, comparisons among the number of alleles of different markers also revealed discordant results: average number of alleles for microsatellites was Ya'an-Wolong > Chengdu > Louguantai but that for DRB and DQA was Louguantai > Chengdu > Ya'an-Wolong (Table 4). The microsatellite-based and DRB-based Fst values disclosed that significant genetic differentiation existed between Ya'an-Wolong/Chengdu and Louguantai (Table 5), in good agreement with their gene sources, i.e. the Ya'anWolong and Chengdu populations were from the nominate Sichuan subspecies while the Louguantai population was from the new Qinling subspecies. On the contrary, the DQA-based Fst estimates revealed significant intra Sichuan subspecies rather than inter subspecies genetic divergence (Table 5).

The inconsistence in heterozygosity, allelic diversity and fixation index among microsatellites, $D R B$ and $D Q A$ should be attributed to the differences in the driving mechanism of polymorphism for different markers and in the identity of individuals sampled in respective studies. The polymorphism of microsatellite loci results from DNA slippage during replication [38] whereas that of MHC genes is pathogen-driven. The neutral variation caused by replication slippage could be accumulated with the evolution of the species, thus predicting long-term evolutionary potential in the face of environmental change. The pathogen-driven MHC polymorphism is dynamic due to continual competition among pathogen variants and the host-pathogen co-evolution, thus being an indicator of ability to cope with short-term pathogen challenges. Scientific conservation plans should consider not only long-term persistence potential but also shortterm survival ability. As a result, conservation geneticists should combine lots of microsatellite markers with multiple MHC loci to examine genetic diversity and population structure in order to obtain an overall result and give unbiased management advice. Despite available genetic data from microsatellite, $D R B$ and $D Q A$, it is a pity that these markers were conducted on different giant panda groups, making it infeasible to design conservation plans from the above-mentioned results at the current stage.

\section{Conclusion}

The DQA allelic diversity of giant pandas was low compared with that of other vertebrates have been investigated. Nonetheless, the giant pandas exhibited more alleles in DQA than those in DRB, suggesting the alpha chain genes would play a critical role when coping with certain pathogens and thus should be included in genetic investigation when intending to design conservation strategies. The microsatellites would accumulate neutral variation whereas the MHC loci could maintain high level of variability during the competition among pathogen variants and the co-evolution between host and pathogen. These two kinds of genetic markers might predict longterm persistence potential and short-term survival ability, respectively. As a result, it is recommended that conserva-

Table 3: Synonymous and non-synonymous substitutions in the 6 DQA alleles of the giant panda. Distances were calculated separately for $A B S$ and non-ABS and the distribution of gene frequency was taken into account. Standard errors were computed using 1000 bootstrap replicates. $N$ is the number of codons in each category and $P$ is the probability that $d_{N}$ and $d_{S}$ are different.

\begin{tabular}{|c|c|c|c|c|c|c|}
\hline Population & Positions & $N$ & $d_{N}$ & $d_{s}$ & $d_{N} / d_{S}$ & $P$ \\
\hline \multirow[t]{3}{*}{ Ya'an-Wolong } & ABS & 21 & $0.022 \pm 0.013$ & $0.000 \pm 0.000$ & $\infty$ & 0.047 \\
\hline & Non-ABS & 70 & $0.014 \pm 0.007$ & $0.011 \pm 0.011$ & 1.273 & $0.44 I$ \\
\hline & All & 91 & $0.016 \pm 0.006$ & $0.010 \pm 0.010$ & 1.600 & 0.259 \\
\hline \multirow[t]{3}{*}{ Chengdu } & $A B S$ & 21 & $0.055 \pm 0.030$ & $0.000 \pm 0.000$ & $\infty$ & 0.033 \\
\hline & Non-ABS & 70 & $0.018 \pm 0.008$ & $0.009 \pm 0.009$ & 2.000 & 0.169 \\
\hline & All & 91 & $0.027 \pm 0.010$ & $0.007 \pm 0.007$ & 3.857 & 0.037 \\
\hline \multirow[t]{3}{*}{ Louguantai } & $A B S$ & 21 & $0.044 \pm 0.021$ & $0.000 \pm 0.000$ & $\infty$ & 0.022 \\
\hline & Non-ABS & 70 & $0.017 \pm 0.007$ & $0.011 \pm 0.011$ & 1.545 & 0.292 \\
\hline & All & 91 & $0.024 \pm 0.008$ & $0.009 \pm 0.009$ & 2.667 & 0.063 \\
\hline \multirow[t]{3}{*}{ All } & ABS & 21 & $0.047 \pm 0.023$ & $0.000 \pm 0.000$ & $\infty$ & 0.020 \\
\hline & Non-ABS & 70 & $0.016 \pm 0.007$ & $0.010 \pm 0.010$ & 1.600 & 0.214 \\
\hline & All & 91 & $0.024 \pm 0.008$ & $0.008 \pm 0.008$ & 3.000 & 0.046 \\
\hline
\end{tabular}


Table 4: Parameters of genetic diversity for the three populations based on different markers.

\begin{tabular}{lcccccc}
\hline & & & & Average number of alleles per locus \\
& Microsatellite & DRB [29] & DQA & Microsatellite & DRB [29] & DQA \\
\hline Ya'an-Wolong & $0.57 / 0.62[36]$ & $0.64 / 0.74$ & $0.65 / 0.71$ & $5.5[36]$ & 4 & 3 \\
Chengdu & null/0.64 [37] & $0.48 / 0.60$ & $0.69 / 0.76$ & $4.5[37]$ & 3 & 5 \\
Louguantai & $0.57 /$ null [18] & $0.73 / 0.81$ & $0.80 / 0.86$ & $3.3[18]$ & 6 & 5 \\
\hline
\end{tabular}

tion geneticists should combine the microsatellite markers with multiple MHC loci to examine genetic diversity and population structure in order to obtain an overall result and give unbiased management advice.

\section{Methods \\ Sampling}

A total of 61 giant pandas were sampled in this study (Table 1). The samples were obtained from the Ya'anWolong Breeding Center $(\mathrm{n}=20)$ and Chengdu Breeding Research Base $(\mathrm{n}=26)$ of Sichuan subspecies and from the Louguantai Saving Center of Rare Wild Animals ( $\mathrm{n}=$ 15) of Qinling subspecies. Whole blood was collected in routine medical examination and stored at $-20^{\circ} \mathrm{C}$. Skin samples were collected from dead individuals over last decade and stored at $-20^{\circ} \mathrm{C}$ until use. Faecal samples were collected within 24 hours post-defecation and dried at $65^{\circ} \mathrm{C}$ overnight. Each dried faecal samples was kept individually in paper bags with silica gel. Genomic DNA was isolated from the blood and skin samples by standard methods [39]. Genomic DNA was extracted from faeces as described by Wan et al. [29].

\section{PCR amplification}

Primers were designed to amplify the second exon of the giant panda $D Q A$ gene, which presumably encodes for the antigen-binding domain of the cell surface molecule [30]. Primers were designed based on DQA consensus regions derived from GenBank sequences (accession number: AY375882 - AY375895, AF343733 - AF343736, U47857 and AJ630363). Primers DQA-up (5'-GCT GAC CAT GTT GCT TAC TAT) and DQA-down (5'-AAG AGG CAG AGC ATT GGA CA) amplify 275 base pairs. The DQA up and down primers hybridize at nucleotide positions 13 to 33 of the exon 2 and 7 to 26 of the intron 2, respectively.

The $20 \mu \mathrm{L}$ reactions contained $10-100$ ng of genomic DNA, $10 \times$ ExTaq buffer $\left(\mathrm{Mg}^{2+}\right.$ plus) (Takara, Shanghai), $0.2 \mathrm{mM}$ of each dNTP, $0.4 \mu \mathrm{M}$ of forward and reverse primers, 1 unit of ExTaq (Takarak Shanghai) and $200 \mu \mathrm{g} /$ $\mathrm{mL}$ of bovine serum albumin (Takara, Shanghai) for genomic DNA from faeces. The cycle conditions consisted of an initial denaturation at $95^{\circ} \mathrm{C}$ for 5 minutes followed by 35 rounds of denaturetion at $95^{\circ} \mathrm{C}$ for 45 seconds, annealing at $56^{\circ} \mathrm{C}$ for 45 seconds and extension at $72^{\circ} \mathrm{C}$ for 45 seconds, with a final extension at $72^{\circ} \mathrm{C}$ for $10 \mathrm{~min}$ utes using a PTC-200 Peltier thermal cycler (M.J. Research Inc. Watertown, MA).Purified PCR product $(5 \mu \mathrm{L})$ was added to $5 \mu \mathrm{L} 2 \times$ gel loading dye buffer containing 95\% formamide, $20 \mu \mathrm{M}$ DETA, $0.05 \%$ bromophenol blue, and $0.05 \%$ xylene cyanol and run in $0.5 \times$ TBE ( 4.5 M TRIS, 4.5 $\mathrm{M}$ boric acid, $1 \mathrm{mM}$ EDTA) for $15-18$ hours at $8^{\circ} \mathrm{C}$. The SSCP bands were visualized by silver staining. The PCRSSCP analysis was conducted three times for each DNA sample and the results were compared to each other.

Cloning and sequence analysisAt least three examples of each allele were cut separately from the gel with a scalpel knife. The DNA was extracted from these gel strips using acrylamaide gel DNA purification kit (Tianwei, Shanghai), and $2 \mu \mathrm{L}$ was used in PCR re-amplification. PCR products were separated on a $1.5 \%$ agarose gel, recovered using the Agarose Gel Extraction Kit (Takara, Shanghai) and then ligated into pUC18 vector. The inserts of positive clones were verified by SSCP and clones with SSCP patterns identical to the genomic band profile were chosen for sequencing. Nine clones for each allele (from three

Table 5: Pairwise Fst indices and their significances (in parentheses; NS = non significant) for the three populations revealed by microsatellites, DRB and DQA.

\begin{tabular}{|c|c|c|c|}
\hline Pairwise comparison & Microsatellite [18] a & $D R B[29]$ & $D Q A$ \\
\hline Ya'an-Wolong Chengdu & 0.07 (NS) & 0.04 (NS) & $0.13(P<0.05)$ \\
\hline Ya'an-Wolong Louguantai & $0.18(P<0.05)$ & $0.13(P<0.05)$ & 0.04 (NS) \\
\hline Chengdu $\sim$ Louguantai & $0.18(P<0.05)$ & $0.18(P<0.05)$ & 0.04 (NS) \\
\hline
\end{tabular}

${ }^{\mathrm{a} G e n e ~ s o u r c e s ~ o f ~ t h e ~ g i a n t ~ p a n d a s ~ i n ~ t h e ~ Y a ' a n-W o l o n g, ~ C h e n g d u ~ a n d ~ L o u g u a n t a i ~ b a s e s ~ w e r e ~ m a i n l y ~ f r o m ~ t h e ~ Q i o n g l a i, ~ M i n s h a n ~ a n d ~ Q i n l i n g ~}$ mountain ranges. As a result, we utilized the Fst indices in the study of Lü et al. [18] (0.07 for Minshan Qionglai, 0.18 for Minshan $\sim$ Qinling and 0.18 for Qionglai Qinling). 
individuals) were sequenced in both directions, using an ABI 3730 sequencer (Applied Biosystems).

\section{Data analysis}

All nucleotide and amino acid sequences were aligned using ClustalW. MEGA2.1 version was used to estimate the number of synonymous nucleotide substitutions per synonymous site $\left(d_{S}\right)$ and the number of nonsynonymous nucleotide substitutions per nonsynonymous site $\left(d_{N}\right)$ using the Nei and Gojobori method with a Jukes-Cantor correction [40]. These calculations were performed independently for the nucleotides within and outside the antigen-binding-sites (ABS) [41]). The ABS and non-ABS of these sequences were assigned after Paliakasis et al. [30] in accordance with human HLA DQA molecule. Expected heterozygosity was calculated after Nei [42] with the small sample size correction and deviation from the HardyWeinberg equilibrium was tested using Markov chain permutation test of 100000 steps in GENEPOP version 3.4 [43]. ARLEQUIN version 2.0 [44] was utilized to calculate Fst indices and the significance was tested using 1000 permutations.

\section{Authors' contributions}

LZ and YFG performed the experiments and LZ drafted the first version of the manuscript. XDR collected the samples and drafted the second version of the manuscript. QHW and SGF provided supervision and revised the manuscript. All authors read and approved the final manuscript.

\section{Acknowledgements}

This work was supported by two grants from the National Nature Science Foundation of People's Republic China (No. 30325009, to Fang SG; No. 30540054, to Wan QH) and a special grant (No. wh04 I 8, to Wan QH) for the giant panda from the China State Forestry Administration.

\section{References}

I. Bernatchez L, Landry C: MHC studies in nonmodel vertebrates: what have we learned about natural selection in 15 years? J Evol Biol 2003, 16:363-377.

2. Janeway CA, Travers P, Walport M, Capra JD: Immunobiology: the immune system in health and disease 4th edition. London: Current Biology Publication; 1999.

3. Apanius $V$, Penn DJ, Slev PR, Ruff LR, Potts WK: The nature of selection on the major histocompatibility complex. Crit Rev Immunol 1997, 17:179-224.

4. Edwards SV, Hedrick PW: Evolution and ecology of MHC molecules: from genomics to sexual selection. Tree 1998, 13:305-31।.

5. Hughes AL, Yeager M: Natural selection at major histocompatibility complex loci of vertebrates. Annu Rev Genet 1998, 32:415-435.

6. Hess CM, Edwards SV: The evolution of the major histocompatibility complex in birds. Bioscience 2002, 52:423-43I.

7. Penn DJ, Damjanovich K, Potts WK: MHC heterozygosity confers a selective advantage against multiple-strain infections. Proc Natl Acad Sci USA 2002, 99: I | 260- | | 264.

8. O'Brien SJ, Roelke ME, Marker L, Newman A, Winkler CA, Meltzer D, Colly L, Evermann JF, Bush M, Wildt DE: Genetic basis for species vulnerability in the Cheetah. Science 1985, 227: I 428-I 434.

9. Watkins D, Garber TL, Chen ZW, Toukatly G, Hughes AL, Letvin NL: Unusually limited nucleotide equence variation of the expressed major histocompatibility complex class I genes of a New World primate species (Saguinus oedipus). Immunogenetics 1991, 33:79-89.

10. WWF MOF: A Comprehensive Survey Report on China's Giant Panda and its Habitat. China Alliance Press \& Hong Kong; 1989.

II. Hu JC, Schaller GB: The giant panda of Wolong. Sichuan Scientific and Technological Publishing House, Chengdu (in Chinese) 1985.

12. Wan QH, Fang SG, Wu H, Fujihara T: Genetic differentiation and subspecies development of the giant panda as revealed by DNA fingerprinting. Electrophoresis 2003, 24:1353-1359.

13. Wan QH, Wu H, Fang SG: A new subspecies of giant panda (Ailuropoda melanoleuca) from Shaanxi, China. J Mammal 2005, 86:397-402.

14. Xie Z, Gipps J: The 2004 international studbook for giant panda (Ailuropoda melanoleuca) Beijing: Chinese Association of Zoological Garden; 2004.

15. Feng WH, Wang RL, Zhong SM, Ye ZY, Cui XZ, Zeng JH: Analysis on the dead cause of the anatomical carcass of giant panda (Ailuropoda melanoleuca). In A study on breeding and disease of the giant panda Edited by: Feng WH, Zhang AJ. Chengdu, Sichuan Scientific and Technical Publishers; 1991:244-248.

16. Ye ZY: The control of the diseases of giant panda in field: report of 50 cases. In A study on breeding and disease of the giant panda Edited by: Feng WH, Zhang AJ. Chengdu, Sichuan Scientific and Technical Publishers; 1991:313-315.

17. Zhang YP, Ryder OA, Fang Z, Zhang H, He T, He G, Zhang A, Fei L, Zhang S, Chen H, Zhang C, Yang M, Zhu F, Peng Z, Pu T, Chen Y, Yao $\mathrm{M}, \mathrm{Gu} \mathrm{W}$ : A study on sequence variation and genetic diversity of the giant panda. Sci in China Ser C 1997, 27:139-144.

18. Lü Z, Johnson WE, Menotti-Raymond M, Yuhki N, Martenson JS, Mainka S, Huang SQ, Zheng Z, Li GH, Pan WS, Mao XR, O'Brien SJ: Patterns of genetic diversity in remaining Giant Panda populations. Conserv Biol 200I, I 5: I596-1607.

19. Einum S, Fleming IA: Genetic divergence and interactions in the wild among native, farmed and hybrid Atlantic salmon. J Fish Biol 1997, 50:634-65I.

20. Fleming IA, Einum S: Experimental test of genetic divergence of farmed from wild Atlantic salmon due to domestication. ICES J Mar Sci 1997, 54:105I-I063.

21. Kallio-Nyberg I, Koljonen M-L: The genetic consequence of hatchery rearing on life-history traits of the Atlantic salmon (Salmo salar L.): A comparative analysis of sea-ranched salmon with wild and reared parents. Aquaculture 1997, 153:207-224.

22. Amills M, Ramiya $V$, Norimine J, Lewin HA: The major histocompatibility complex of ruminants. Rev Sci Tech 1998, 17:108-120.

23. Bowen L, Aldridge BM, Gulland F, Woo J, Van Bonn W, DeLong R, Stott JL, Johnson ML: Molecular characterization of expressed $D Q A$ and $D Q B$ genes in the California sea lion (Zalophus californianus). Immunogenetics 2002, 54:332-347.

24. Kennedy LJ, Hall LS, Carter SD, Barnes A, Bell S, Bennett D, Ollier B, Thomson W: Identification of further DLA-DRBI and DQAI alleles in the dog. Eur J Immunogenet 2000, 27:25-28.

25. Lehman N, Decker DJ, Stewart BS: Divergent patterns of variation in major histocompatibility complex class II alleles among Antarctic phocid pinnipeds. J Mammal 2004, 85: $1215-1224$.

26. Polvi A, Garden OA, Elwood CM, Sorensen SH, Batt RM, Maki M, Partanen J: Canine major histocompatibility complex genes DQA and DQB in Irish setter dogs. Tissue Antigens 1997, 49:236-243.

27. Vage DI, Olsaker I, Ronningen K, Lie O: Partial sequence of an expressed major histocompatibility complex gene (DQA) from artic fox (Alopex lagopus). Anim Biotechnol 1994, 5:65-68.

28. Wagner JL, Burnett RC, DeRose SA, Storb R: Molecular analysis and polymorphism of the DLA-DQA gene. Tissue Antigens 1996, 48:199-204.

29. Wan QH, Zhu L, Wu H, Fang SG: Major histocompatibility complex class II variation in the giant panda (Ailuropoda melanoleuca). Mol Ecol 2006, 15:244 I-2450.

30. Paliakasis K, Routsias J, Petratos K, Ouzounis C, Kokkinidis M, Papadopoulos GK: Novel structural features of the human histocompatibility molecules HLA-DQ as revealed by modeling based on the published structure of the related molecule HLA-DR. J Struct Biol 1996, I I 7:145-163. 
31. Brown JH, Jardetzky TS, Gorga JC, Stern LJ, Urban RG, Strominger JL, Wiley DC: Three-dimensional structure of the human class II histocompatibility antigen. Nature 1993, 364:33-39.

32. Zhou H, Hickford JG: Allelic polymorphism in the ovine DQA gene. J Anim Sci 2004, 82:8-16.

33. Fraser DG, Bailey E: Polymorphism and multiple loci for the horse DQA gene. Immunogenetics 1998, 47:487-490.

34. DeFransco AL, Locksley RM, Robertson M: The MHC and polymorphism of MHC molecules. In Immunity: The Immune Response in Infectious and Inflammatory Disease Published online, New Science Press Ltd; 2007.

35. Hugh M: Evolution of MHC class II allelic diversity. Immunol Rev 1995, 143:II3-122.

36. Yan L, Huang Y, Zhang BW, Zhang SN, Zhang HM, Wei FW, Wang PY, Li M: Status and prognosis of genetic diversity in captive giant pandas(Ailuropoda mela noleuca)in Wolong. Acta Theriologica Sinica 2006, 26:317-324. (in Chinese)

37. Zhang ZH, Shen FJ, Sun S, Davil VA, Zhang AJ, O'Brien SJ: Paternity Assignment of Giant Pan da by $M$ icrosatellite Genotyping. Hereditas 2003, 25:504-5I 0. (in Chinese)

38. Levinson G, Gutman GA: Slipped-strand mispairing: a major mechanism for DNA sequence evolution. Mol Biol Evol 1987 4:203-221.

39. Sambrook J, Russell DW: Molecular cloning: a laboratory manual, 3rd edn. Cold Spring Harbor Laboratory Press, New York, NY; 2001.

40. Kumar S, Tamura K, Jakobsen IB, Nei M: Mega2: molecular evolutionary genetics analysis software. Bioinformatics 200I, 1 7:1244-1245.

4I. Hughes AL, Nei M: Pattern of nucleotide substitution at major histocompatibility complex class I loci reveals overdominant selection. Nature 1988, 335:167-170.

42. Nei M: Molecular Evolutionary Genetics New York: Columbia University Press; 1987.

43. Raymond M, Rousset F: GENEPOP (version I.2): Population genetics software for exact tests and ecumenicism. J Heredity 1995, 86:248-249.

44. Schneider S, Roessli D, Excoffier L: Arlequin, Version 2.000: A Software for Population Genetic Data Analysis. In Genetics and Biometry Laboratory Volume 91. University of Geneva, Switzerland; 2000:3166-3170

Publish with Bio Med Central and every scientist can read your work free of charge

"BioMed Central will be the most significant development for disseminating the results of biomedical research in our lifetime. "

Sir Paul Nurse, Cancer Research UK

Your research papers will be:

- available free of charge to the entire biomedical community

- peer reviewed and published immediately upon acceptance

- cited in PubMed and archived on PubMed Central

- yours - you keep the copyright 